Proceeding Paper

\title{
Training and Equipping Chainsaw Operators and Occupational Safety in Polish Forests ${ }^{\dagger}$
}

\author{
Arkadiusz Gendek ${ }^{1, *}$, Monika Aniszewska ${ }^{1}$, Tomasz Nurek ${ }^{1}$ and Tadeusz Moskalik ${ }^{2}$ \\ 1 Department of Biosystems Engineering, Institute of Mechanical Engineering, Warsaw University of Life \\ Sciences-SGGW, Nowoursynowska 164, 02-787 Warsaw, Poland; \\ monika_aniszewska@sggw.edu.pl (M.A.); tomasz_nurek@sggw.edu.pl (T.N.) \\ 2 Department of Forest Utilization, Institute of Forest Sciences, Warsaw University of Life Sciences-SGGW, \\ Nowoursynowska 159, 02-787 Warsaw, Poland; tadeusz_moskalik@sggw.edu.pl \\ * Correspondence: arkadiusz_gendek@sggw.edu.pl \\ + Presented at the 1st International Electronic Conference on Forests-Forests for a Better Future: Sustainability, \\ Innovation, Interdisciplinarity, 15-30 November 2020; Available online: https://iecf2020.sciforum.net.
}

Citation: Gendek, A.; Aniszewska, M.; Nurek, T.; Moskalik, T. Training and Equipping Chainsaw Operators and Occupational Safety in Polish Forests. Environ. Sci. Proc. 2021, 3, 55. https://doi.org/10.3390/IECF202008057

Academic Editors: Angela Lo Monaco, Cate Macinnis-Ng and Om P. Rajora

Published: 13 November 2020

Publisher's Note: MDPI stays neutral with regard to jurisdictional claims in published maps and institutional affiliations.

Copyright: $(2020$ by the authors. Licensee MDPI, Basel, Switzerland. This article is an open access article distributed under the terms and conditions of the Creative Commons Attribution (CC BY) license (http://creativecommons.org/licenses/by/4.0/).

\begin{abstract}
Despite the introduction of an increasing number of multi-purpose machines, timber harvesting is still conducted in Polish forests mainly at the manual-machine level. The basic tool used in the process of felling, delimbing, and bucking is the petrol chainsaw. In order to ensure safety at work, chainsaw operators are required to have adequate knowledge of the saw's operation, how to work with it, as well as on the use of appropriate auxiliary equipment and personal protective measures. Polish regulations require that a logger starting work must complete appropriate training and obtain a license to harvest trees. The aim of this study was the assessment of trainings provided for chainsaw operators and identification of the potential hazards by logging operations. In order to assess the state of training of chainsaw operators and their occupational safety during logging, a survey was conducted. The survey covered 15 forest districts. Questionnaires were delivered to 354 chainsaw operators, of whom 209 completed and returned the forms. Most operators of chainsaws receive the necessary information on safety work by logging operation. However, a significant group of operators does not use personal protective equipment, which could be a potential cause of accidents.
\end{abstract}

Keywords: occupational safety; chainsaw operator; vocational training course; personal protective equipment

\section{Introduction}

Wood harvesting in Poland mainly takes place at the manual-machine level, with the petrol chainsaw being the primary tool of the logger in this work. Logging work is in the group of high-risk occupations [1]. To ensure work safety, chainsaw operators are required to know how to harvest trees with a chainsaw, including the rules on felling, the operation and maintenance of chainsaws and first aid procedures in case of an accident. Knowledge about the dangers of logging work, including occupational diseases, is also important.

Before being employed in the forest, a logger is required to have completed appropriate training and obtained the petrol chainsaw operator license. Various institutions provide such courses and training, e.g., universities, business foundations, educational institutions, and other business entities. The scope of training does not always meet the standards set by the Director General of State Forests, and also, not all training providers are concerned with the quality of the knowledge provided, not only theoretical but practical as well. 
Four aspects determined the need for this study: (1) The widespread use of chainsaws for wood harvesting in the forest; (2) reports about the unsatisfactory quality of the training provided, including the diverse range of training courses and the lack of a uniform curriculum in the courses entitling a person to practice logging [2,3]; (3) identification of the potential hazards of operating a chainsaw [4]; (4) analysis of accidents at work involving chainsaws, indicating that they are mainly caused by the improper actions of the employee [5].

\section{Materials and Methods}

A questionnaire survey was conducted to obtain data for the study [6]. The questionnaire included single- and multiple-choice questions, as well as open questions requiring a short written statement. The questionnaire was selective. It was delivered to chainsaw operators through the employees of State Forests, the Polish Post Office, third parties, and personally.

The target study subjects were operators of portable chainsaws, working in wood harvesting in fifteen forest districts located in the Regional Directorates of State Forests in Białystok, Katowice, Olsztyn, and Radom. A total of 354 questionnaires were distributed to the chainsaw operators, of which 209 were received. Eight questionnaires were rejected because they were incomplete. The responses to the questionnaires were coded and the data were processed using Statistica v.13.3.

\section{Results and Discussion}

The largest group of respondents were loggers between 41 and 45 years of age (23\%). The second group in terms of numbers were respondents aged $46-50$ years (21\%) and then $36-40$ years $-20 \%$. Therefore, it can be concluded that the majority were chainsaw operators in their prime age range (36-50 years). The remaining age groups - up to 35 and over 50 years of age-constituted $19 \%$ and $15 \%$ of respondents, respectively. The age structure was transformed to the normal distribution.

The main form of employment of the respondents was a full-time job in forest service companies $(77 \%)$. Ten percent of the surveyed population were occasional $(7 \%)$ or seasonal (3\%) forest workers, employed mainly when there is an increased intensity of forestry work or a shortage of full-time employees. Self-employment, i.e., operating one's own business, was indicated by $12 \%$ of the respondents.

In analyzing the self-assessment of the chainsaw operators, the questionnaires showed that on a skills scale from 1 to 10 (1 indicating a low self-assessment and 10 indicating a high self-assessment), the operators most often chose $8(31 \%)$. The values of 7 and 9 were each chosen by $21 \%$ of the respondents; the value $6-12 \%$; the value $10-12 \%$; the value $5-4 \%$; and the value $4-$ only $1 \%$ of the respondents. None of the surveyed operators indicated a value of 3 or less on the scale. The surveyed loggers were convinced of their high professional skills - a total of $64 \%$ of ratings were at 8 or more. Having a high selfassessment of one's skills may lead to adopting a routine approach and not following safety rules and other safety recommendations, which was confirmed by Brzózko et al. [7].

On the basis of the results obtained, the average self-assessment value of chainsaw operators in particular age groups was determined. The analysis of variance $\left(\mathrm{F}_{(7,191)}=\right.$ $1.5652 ; p=0.1459$ ) did not show any differences between the results of self-assessment in particular age groups; therefore, all the results can be considered homogeneous. The average self-assessment of chainsaw operators was $7.84(\mathrm{SD}=1.36$; $\mathrm{SE}=0.1)$. A small correlation ( $r=0.3194)$ was observed between the self-assessment value and the period of being licensed as a logger. The longer loggers were licensed to practice the profession, the higher their skills were assessed.

An important factor affecting work safety is work experience, which may be the cause of many problems, from breaks at work to accidents or injuries. In analyzing the relationship between work experience and the age of loggers, one can conclude that there 
these variables are significantly correlated. When relating the length of service to the age of the operators and their relevant age group, there was a statistically significant relationship between these parameters $(r=0.7010)$. The older the operator is, the longer he has worked as a logger.

In order to work as a logger, a license is required to operate a petrol chainsaw. A license can be obtained by attending training courses. Research shows that the most popular form of training was a course lasting about 2 weeks. Such courses were completed by $89 \%$ of the surveyed operators. In turn, $7 \%$ of the operators completed a course lasting only 2-3 days. One could surmise that the knowledge provided during such a course was heavily reduced and insufficient to convey important health and safety issues or tree felling techniques. One could also assume that this was a course on the operation of a petrol chainsaw, and not a course entitling the graduate to work as a logger. Four percent of the respondents indicated a course lasting 4 weeks (about 18 days), and 3\% pointed to a different time period. The analysis of variance $\left(\mathrm{F}_{(3,195)}=0.9341 ; p=0.4251\right)$ did not show any influence of course duration on the self-assessment of chainsaw operators. This may indicate that those attending the courses for several days were already familiar with the use of a chainsaw and that the completion of the course was only needed to obtain the required certificate.

A large group of chainsaw operators obtained their skills from a friend or on their own. Such a result may suggest that they had learned to operate a chainsaw before completing a course or training in the field. They may also have been among those who used a chainsaw for work around their homes. It should be remembered, however, that the knowledge gained from a friend or independently may be erroneous because of the incorrect habits of the learner or due to a mistaken interpretation of certain instructions or regulations when learning on their own.

The construction of a chainsaw also affects the safety of the operator during logging. Survey results showed that a large group of respondents are aware of the risk of kickback and consistently use anti-kickback chainsaws for work (38\% of chainsaw operators); $13 \%$ use them sometimes. The remaining respondents use chainsaws of a standard construction.

One way to protect the health and life of a chainsaw operator is the use of personal protective equipment. Survey results showed that $93 \%$ of the respondents used a safety helmet at all times, $6 \%$ only occasionally, and $1 \%$ did not use helmets. Hearing defenders were not used at all by $2 \%$ of the surveyed operators, only sometimes by $9 \%$, while $89 \%$ stated that they always work using hearing defenders. The use of goggles or a visor was declared by $81 \%$ of the operators, $3 \%$ did not protect their eyes at all, and $16 \%$ protected them only occasionally. Protective gloves were used by $89 \%$ of the operators, $8 \%$ used them sometimes, $3 \%$ did not use them at all, while $1 \%$ use them only in winter. Given the various types of this protective measure, only $26 \%$ of those surveyed used gloves with anti-vibration pads, while the remaining $74 \%$ of forestry chainsaw operators wore regular gloves. Chainsaw trousers play a very important role in protecting an operator from the dangerous consequences of direct contact with a working saw. The study showed that $83 \%$ of the respondents used chainsaw trousers, while $10 \%$ used chainsaw chaps on their pants. The remaining $7 \%$ of loggers worked in ordinary trousers during the logging process. This may indicate negligence on the part of the work organizer or the chainsaw operator's failure to comply with health and safety regulations. Another condition for safe work in the forest is the use of appropriate footwear. Footwear should protect against moisture, direct contact with water, and being cut. The use of ordinary athletic type of shoes was indicated by $3 \%$ of the surveyed population, the use of shoes with hard soles was indicated by $46 \%$, and $52 \%$ used shoes equipped with a protective insole for the toes and ankle. An important element of a complete chainsaw operator's set of clothing is the work jacket. According to the study, $11 \%$ of chainsaw operators work in ordinary jackets during logging in the forest and $89 \%$ in jackets of bright, clearly visible colors.

Cutting and felling trees is a task that requires the observance of relevant health and safety regulations and the application of the principles of cutting and felling techniques. 
In the survey, $92 \%$ of the respondents admitted to using wedges when cutting and felling thick trees, $5 \%$ do not use them at all, and 3\% only sometimes. In the case of logging in the younger age class stands-during the felling of thin trees, $41 \%$ of loggers did not work with an assistant, $27 \%$ only sometimes, and $32 \%$ of the surveyed loggers worked with an additional person. Before proceeding to fell trees, the work area should be prepared. Survey results show that only $26 \%$ of the chainsaw operators de-bark the trunk of the tree to be felled, $33 \%$ do so sometimes, and the remaining respondents (41\%) do not debark the trunk before felling. Chainsaw operators have a much higher awareness of their safety in terms of preparing a safe distance escape path from the strike zone when felling trees. According to the survey, $72 \%$ of the respondents prepare such a path, $21 \%$ do it sometimes, and $7 \%$ do not prepare one at all.

The moment of starting up a chainsaw is when an injury can occur. It is recommended that the chain brake be applied when the saw is started to prevent it from moving along the bar. Meanwhile, $36 \%$ of those surveyed have the brake on and safely start the saw, $40 \%$ have the brake off and the saw can move along the guide bar immediately after starting the engine, and the remaining $25 \%$ do not pay attention to the position of the brake lever.

The survey showed that $25 \%$ of the respondents were involved in an accident or other injury while performing logging work in the forest. Among those who had suffered an accident, $35 \%$ were injured due to tripping or slipping, $25 \%$ were injured as a tree was being felled or by a falling branch, $20 \%$ were injured due to a safety failure, $12 \%$ because of not using personal protective equipment, and $2 \%$ due to the improper use of working tools, while $6 \%$ did not clearly specify the cause of their accident.

The accidents most frequently resulted in fractures or sprains/dislocations (25\%) and bruises (25\%). Skin and muscle cuts and other various types of wounds were indicated by $20 \%$ of the respondents, while $10 \%$ of the loggers indicated the simultaneous occurrence of various types of wounds. Of particular concern is the fact that only $24 \%$ of the affected loggers reported the incident as an accident at work.

\section{Conclusions}

Most operators of petrol chainsaws receive the necessary information on chainsaw construction and operation, felling technology, workplace safety, or first aid as part of the chainsaw operator's course. However, a significant group of operators $(7 \%)$ only completed 2-3-day courses.

The lack of the use of personal protective equipment is a worrisome phenomenon. It turns out that only half of the respondents use footwear with a protective insole for their toes and ankles. Failure to use appropriate footwear should be considered a gross violation of health and safety rules.

Every fourth chainsaw operator in this study experienced an accident or injuries while working with a chain saw. A very high percentage $(76 \%)$ of injuries and incidents relating to employee health and safety were not reported as accidents occurring at work.

Due to the natural process of forgetting the knowledge gained through learning, continuing education courses and training are recommended, which should be a permanent element of the occupational health and safety system in all companies providing logging services.

Author Contributions: Conceived and designed the study, A.G.; implemented the study, A.G. and M.A.; analyzed the data, A.G., M.A., T.N. and T.M.; writing-original draft preparation, review and editing, A.G., M.A., T.N., and T.M.; supervision, A.G. All authors have read and agreed to the published version of the manuscript.

Conflicts of Interest: The authors declare no conflicts of interest. 


\section{References}

1. Blombäck, P.; Poschen, P.; Lövgren, M. Employment Trends and Prospects in the European Forest Sector: A Study Prepared for the European Forest Sector Outlook Study (EFSOS); Geneva Timber and Forest Discussion Papers; United Nations: New York, NY, USA; Geneva, Switzerland, 2003; ISBN 978-92-1-116843-3.

2. Wirth, O.; Sigurdsson, S.O. When workplace safety depends on behavior change: Topics for behavioral safety research. J. Saf. Res. 2008, 39, 589-598, doi:10.1016/j.jsr.2008.10.005.

3. Huang, Y.-H.; Ho, M.; Smith, G.S.; Chen, P.Y. Safety climate and self-reported injury: Assessing the mediating role of employee safety control. Accid. Anal. Prev. 2006, 38, 425-433, doi:10.1016/j.aap.2005.07.002.

4. Nowacka, W. Occupational diseases in Polish forestry sector-An increasing problem. Nauka Przyroda Technol. 2012, 6, 1-10.

5. Wilson-Donnelly, K.A.; Priest, H.A.; Salas, E.; Burke, C.S. The impact of organizational practices on safety in manufacturing: A review and reappraisal. Hum. Factors Ergon. Manuf. Ser. Ind. 2005, 15, 133-176, doi:10.1002/hfm.20000.

6. Gendek, A.; Aniszewska, M.; Nurek, T.; Moskalik, T. State of training and equipment of chainsaw operators employed for timber harvesting in Polish forests. Sylwan 2018, 162, 118-126, doi:10.26202/sylwan.2017110.

7. Brzozko, J.; Skarżyński, J.; Wójcik, K.; Rednowski, M. Experience of the woodcutter and the risk of an accident during the tree felling. Sylwan 2016, 160, 452-458, doi:10.26202/sylwan.2015153. 